Schwefelkiese vor, die W. Casselmann untersuchte. Das analysirte Stïck bestand aus zwei scharf von einander gesonderten Partien.

Der eine Theil ähnelte seiner Farbe nach mehr einem Schwefelkies als einem Kupferkies und war mehrfach von ganz dünnen, wahrscheinlich durch Verwitterung entstandenen oxydischen Schnüren durchzogen. Seine Zusammensetzung entsprach sehr nahe einem Verhältnisse von gleichen Aequivalenten Kupfer- und Nickelkies, in welchem $2 / 5$ des Nickels durch eine äquivalente Menge Eisen ersetzt ist, nach der Formel:

$\left(\mathrm{Cu}^{2} \mathrm{~S}+\mathrm{Fe}^{2} \mathrm{~S}^{3}\right)+\mathrm{Fe}^{2} / 5 / \mathrm{S}$. Der andere Theil des Minerals hatte eine unbestimmt bräunliche Farbe und stellte sich als ein Gemenge derselben Bestandtheile, welche den ersten Theil bilden, mit Bitterspath, Spatheisenstein, Schwefelkies, Wismuthglanz, Rotheisenstein, Quarz und geringen Spuren von Arsenmetallen und alkalihaltigen Silicaten heraus.

Hiernach und nach Untersuchungen derselben Erze von andern Chemikern scheint es, dass das in den Dillenburger Erzen vorkommende Schwefelnickel nicht etwa mit andern Schwefelmetallen unmittelbar in chemischen Verbindungen vorhanden ist, welche etwa nach Art der Kupferkiese nach bestimmten stöchiometrischen Proportionen gebildet sind, sondern dass in demselben eine Substituirung wechselnder Mengen Nickel durch äquivalente Mengen Eisen statt gefunden hat, und dass die so gebildeten Substitutionsproducte wieder mit andern Schwefelmetallen in chemische Verbindungen getreten sind. (Ann. d. Chem. u. Pharm. CXV. 338-345.) G.

\title{
Ueber schwarze Schreibtinten
}

hat James Starck interessante und zahlreiche Versuche angestellt, welche zeigen, dass der gewöhnliche grüne Eisenvitriol des Handels das beste Eisensalz zur Tintenbereitung abgiebt. Der Zusatz von salpetersaurem oder salzsaurem Eisenoxyd erhöht zwar die Schwärze der Tinte, aber dies nur auf Kosten der Dauerhaftigkeit der der damit gemachten Schriftzüge.

Die duucrhaftesten Tinten sind nach Starck die aus guten Galläpfeln, Eisenvitriol und Gummi zusammengesetzten. Das beste Verhältniss ist nach seinen Versuchen 6 Th. Galläpfel auf 4 Th. Eisenvitriol. Mit sol- 
cher Tinte angefertigte Schrift wurde ein Jahr lang der Luft und den Sonnenstrahlen ausgesetzt, obne dass nachher die geringste Veränderung davon wahrzunehmen gewesen wäre, während die Schrift, die mit andern Tintenarten, oder mit Tinten, in denen das Verhältniss der Bestandtheile ein anderes, wie oben gemacht worden, unter gleichen Umständen mehr oder weniger verändert wurde. Endlich setzt diese Tinte keinen Niederschlag des darin enthaltenen Eisen-Gallotanats ab, was zu der Dauerhaftigkeit der Schriftzüge wesentlich beiträgt.

Tinten, in denen ein Theil der Galläpfel durch Campechenholz ersetzt wird, sind weniger dauerhaft, als die nur aus Galläpfeln bereiteten.

Das passendste Mittel, die Schwärze der Tinte möglichst zu erböhen, fand Starck in der Indigolösung. Wird diese gewöhnlicher Eisentinte in einem angemessenen Verhältnisse zugesetzt, so erhält man eine Flüssigkeit, welche leicht aus der Feder fliesst, und nicht absetzt. Die damit gemachten Schriftziige sind frisch auf dem Papiere gut sichtbar, zeigen trocken eine tief schöne Schwärze, und verblassen niemals.

Nach Starck ist folgende Vorschrift die beste:

Galläpfel ......... 375 Theile

Indigolösung $\ldots \ldots \ldots \ldots 250$ n

Grüner Eisenvitriol .....250

Arabisches Gummi ...... $125-180$ Th.

Gewürznelken .......... 2 Theile

Wasser so viel, als erforderlich, um $2000 \mathrm{Th}$. Tinte zu erhalten.

Schliesslich emptiehit Starck zur Anfertigung wichtiger Schriftstïcke den Gebrauch der Gänsefeder, da durch die Berührung mit der Metallfeder auch die beste Tinte in ihrer Dauerhaftigkeit mehr oder weniger beein. trächtigt wird. (Journ. of the Franklin Instit. - Journ. de Pharm. et de Chim. Octbr. 1859. pag. 283 etc.) Hendess.

\section{Veber eine neue Methode der Bleiweissfabrikation und über eine Ursache des Vergelbens der Bleiweissanstriche.}

Dr. Grüneberg bringt gekörntes Blei in horizontal um ihre Achse rotirenden sechsseitigen Cylindern von Thon in Bewegung, während gleichzeitiger Einwirkung von Luft, Essigsäure und Kohlensäure, wobei Luftund Kohlensäure durch Oeffnungen im Boden der Cylinder einströmen, Essigsäure und Kohlensäure aber durch 